\title{
O CAPITALISMO COORDENADO ALEMÃO: DO BOOM DO PÓS-GUERRA À AGENDA 2010
}

Alexandre Queiroz Guimarães

A Alemanha apresentou nas décadas que se seguiram à Segunda Guerra Mundial uma performance econômica muito favorável: a taxa de crescimento anual foi de $8,2 \%$ entre 1950 e 1960 e de 4,4\% entre 1960 e 1973 (Coates, 2000:05). A produtividade também subiu significativamente: $5,9 \%$ ao ano entre 1950 e $1973^{1}$. A despeito do seu tamanho limitado, a Alemanha tornou-se o maior país exportador do mundo, com uma pauta muito diversificada, demonstrando capacidade de competição em vários setores. Esses resultados foram alcançados ao lado de indicadores sociais também muito positivos: salários elevados, distribuição de renda entre as melhores do mundo desenvolvido, taxas de pobreza e criminalidade muito baixas, um abrangente Welfare State e desemprego praticamente nulo.

Muitos fatores favoreceram o bom desempenho econômico. Os anos do pós-guerra foram de forte crescimento

1. Utilizou-se aqui o PIB por hora trabalhada, que, no mesmo período, cresceu 2,5\% nos Estados Unidos. Para o período 1973-1987, o aumento da produtividade na Alemanha foi de 2,6\% ao ano, enquanto nos Estados Unidos foi de $1 \%$ ao ano (Coates, 2000: 26). 
do comércio e da economia mundial. A Alemanha também se beneficiou amplamente das possibilidades de convergência, utilizando tecnologias e técnicas organizacionais disponíveis em países mais avançados, especialmente os Estados Unidos. Em terceiro lugar, a relação privilegiada com os Estados Unidos, responsável também pela defesa do país, permitiu que os recursos e o esforço fossem concentrados na economia. Em quarto lugar, as iniciativas de integração européia representaram grande estímulo às exportações.

O ponto que interessa aqui destacar relaciona-se à particularidade institucional da organização do capitalismo alemão, batizado por alguns autores de capitalismo coordenado, ou capitalismo socialmente organizado (Streeck, 1997; Soskice, 1999; Coates, 2000). A organização do capitalismo alemão apresenta, desde o pós-guerra, particularidades institucionais que muito o diferencia dos modelos de capitalismo liberal, praticados nos Estados Unidos e no Reino Unido². 24 Diferentemente desses países, em que as relações econômicas são, basicamente, reguladas pelo mercado e por hierarquias, o capitalismo alemão conta com vários mecanismos de regulação via networks, em que associações empresariais e sindicatos desempenham grande papel. Uma configuração institucional muito própria confere resultados bem particulares ao modelo, com fortes implicações em termos de vantagens comparativas, políticas adotadas e resultados sociais.

O objetivo deste artigo é explorar essas particularidades, mostrando como a consolidação de uma relação sistêmica, com forte interdependência entre diversas áreas do modelo, teve significativas implicações para a configuração da economia alemã. Procura-se, inicialmente, caracterizar o modelo e mostrar como ele foi consolidado durante as décadas de prosperidade do pós-guerra. Posteriormente,

2. Para uma consideração sobre o paradigma 'Variedades de Capitalismo' e suas implicações para a economia dos países, veja Soskice e Hall (2001), Soskice (1999) e Guimarães (2005). 
explora-se como, em face das pressões e dos desafios recentes, o modelo vem se reestruturando. Procura-se mostrar que, apesar das forças de mudança, das pressões que vêm colocando o modelo socialmente regulado em xeque e das respostas recentes do governo, incluindo o programa Agenda $2010^{3}$, o capitalismo alemão continua distinto. Ele vem procurando adaptar-se ao novo contexto, mas os traços centrais do arranjo, com destaque para as relações de trabalho, continuam intactos. Nesse processo, tanto os desafios atuais quanto a forma como a Alemanha vem respondendo a eles são centrais para as perspectivas futuras da economia alemã.

\section{A estruturação do modelo no pós-guerra}

A reconstrução do capitalismo alemão após a Segunda Guerra Mundial foi marcada por uma grande preocupação em atingir a legitimidade e em resgatar o apoio das classes sociais, depois da traumática experiência do nazismo. Procurou-se, desde o início, obter o apoio dos sindicatos, concedendo canais de participação aos trabalhadores em troca de posições menos radicais e contestatórias (Streeck, 1997). Da mesma forma, encorajou-se o fortalecimento das associações empresariais, que, ao lado dos sindicatos, foram estimuladas a desempenhar funções quase públicas. O capitalismo assumiu, assim, um molde social. Embora mantendo as relações básicas de um capitalismo de mercado, deveria ser socialmente responsável. Tal posicionamento refletia-se na estrutura de decisões das empresas, em que trabalhadores, bancos e outros stakeholders tinham canais de participação e influência nas decisões (Streeck, 1997:37).

Assim, um dos traços distintivos do capitalismo coordenado alemão é a forte participação dos trabalhadores, consolidada no modelo de relações industriais. Essa participação se dá em termos tanto de negociações coletivas, conduzidas

3. Amplo programa de reformas apresentado por Schröeder em 2003. 
por sindicatos fortes e abrangentes, como das empresas, em que conselhos de trabalho independentes têm participação, garantida por lei, nas decisões ligadas às políticas de pessoal e emprego (Thelen e Kume, 2003: 186). Em nível nacional, sindicatos bem representativos favorecem soluções negociadas, contribuindo para reajustes salariais coordenados e baixos índices de inflação ${ }^{4}$. Em nível das firmas, os conselhos de trabalho têm autonomia e flexibilidade em várias questões, mas são monitorados pelos sindicatos, de forma a cumprir as regras do acordo coletivo.

De um lado, a forte participação dos trabalhadores pode ser vista como um mecanismo de restrição à ação dos gerentes, limitando sua capacidade de demitir ou de reduzir salários. Mas de outro lado, o sistema de relações industriais transforma os trabalhadores em parceiros, em nível tanto das negociações coletivas como das firmas. Como será desenvolvido adiante, mecanismos de participação nas deci26 sões das firmas e de proteção ao emprego desempenham importante papel em um modelo de capitalismo cuja capacidade competitiva está muito ligada à qualificação dos trabalhadores e à sua capacidade de gerar inovações incrementais.

Um segundo aspecto central do capitalismo coordenado alemão é o papel desempenhado pelas associações empresariais, as quais são responsáveis pela regulação de vários quesitos ligados à indústria, inclusive a qualidade do produto. As associações cumprem a importante função de incentivar e possibilitar a colaboração, monitorando o processo, arbitrando conflitos e permitindo a superação do dilema da ação coletiva. Ao fazerem isso, estimulam as

4. Esse mecanismo demonstrou, até os anos 80, vantagens em relação às negociações isoladas, contribuindo para as taxas de desemprego e inflação relativamente baixas nos anos 70 e 80 (Hall, 1999). Outro aspecto a destacar é a contribuição da negociação salarial para menor dispersão salarial, com efeitos positivos sobre a distribuição de renda (Streeck, 1997: 36). 
empresas a trocarem informações e experiências, engajando-se em redes de cooperação que têm fortes implicações para a capacidade competitiva do respectivo setor. Como argumenta Soskice (1999: 116), a colaboração entre as firmas, arbitrada pelas associações, desempenha papel importante no processo de transferência de tecnologia, no desenvolvimento do produto, na definição de componentes e em outras etapas 5 . Da mesma forma, os vínculos entre firmas, associações e instituições especializadas, gerando expertise, desempenham significativo papel em atividades de pesquisa e desenvolvimento.

Além do estímulo à colaboração entre as firmas, as associações são fundamentais para reduzir a desconfiança das empresas em relação ao governo, encorajando-as a engajarem-se em programas conjuntos em áreas de treinamento, pesquisa e transferência de tecnologia. Enfim, ao arbitrar o processo de colaboração com os conselhos de trabalho, funcionando como árbitros capazes de resolver possíveis conflitos, as associações também desempenham importante papel nas relações de cooperação internas à firma, incentivando o engajamento necessário à consolidação de habilidades específicas à indústria e à firma.

Em síntese, a ação das associações é elemento central desse modelo de capitalismo coordenado, em que a coordenação se dá, essencialmente, a partir dos setores produtivos $^{6}$. Gerar a capacidade empresarial que possibilite esse tipo de cooperação e coordenação não é tarefa fácil, requerendo um amplo processo de consolidação de relações cooperativas. $\mathrm{O}$ incentivo para colaborar depende da existência

5. Segundo Soskice (1999: 117), a alta colaboração é favorecida por estratégias que privilegiam a diferenciação do produto, evitando a competição direta por clientes de outras empresas.

6. O outro tipo de capitalismo coordenado é o capitalismo japonês, em que a coordenação se dá, basicamente, dentro dos grupos empresariais (Hall e Soskice, 2001). 
de um arranjo que, ao gerar confiança e ao resolver o dilema da ação coletiva, torne a colaboração racional. Requer também a convicção de que as informações compartilhadas não serão usadas indevidamente ${ }^{7}$.

Sindicatos e associações empresariais exercem um papel ativo no engajamento em programas de treinamento, que são de alta qualidade e gozam de alto status. Bons conhecedores das necessidades da indústria, o envolvimento deles é fundamental para gerar as capacitações necessárias para manter a sua excelência e capacidade competitiva. O processo de treinamento ilustra bem a importância das networks para o funcionamento do modelo, o que não se limita apenas à parceria de associações empresariais, trabalhadores e agências públicas. As empresas precisam que os trabalhadores desenvolvam habilidades específicas tanto para a indústria como para a própria firma. Dependem, pois, de agências especializadas para o desenvolvimento de habilidades 28 setoriais. Nesse processo, as empresas acabam abrindo suas informações, condição para que as habilidades específicas à indústria sejam ajustadas às demandas específicas das firmas (Soskice, 1999: 109). Assim, precisam estar confiantes de que as informações não serão usadas de forma indevida. A ação das associações e o comportamento cooperativo que se organiza em torno delas fortalecem esta confiança.

Nesse ponto, vale destacar a importância ímpar do sistema de treinamento para o modelo de capitalismo alemão. Inicialmente, destaca-se a parceria entre as empresas e as escolas, que já preparam os futuros trabalhadores com as habilidades que serão depois úteis às firmas (Estevez-Abe, Iversen e Soskice, 2001: 156-157). Depois que os indivídu-

7. Na inexistência de associações fortes e da consolidação de práticas de cooperação, o comportamento racional é a estratégia individual. As firmas não cooperam e não trocam informações, e os sindicatos, ao invés de parceiros, são vistos como entraves ao funcionamento das empresas. Esta é a realidade encontrada em países de capitalismo liberal (Soskice, 1999; Hall e Soskice, 2001). 
os deixam a escola, as firmas oferecem a eles contratos de trabalho temporários, que duram o tempo de aprendizagem (Jürgens, 2003: 219). Um aspecto digno de nota são as oportunidades dadas aos trabalhadores sem habilidades acadêmicas, os quais recebem qualificações que lhes abrem acesso a oportunidades de emprego. Isso tem grande impacto em termos sociais e distributivos, diferenciando muito o modelo alemão dos casos de capitalismo liberal, em que esses trabalhadores ficam condenados a empregos precários e a salários muito baixos (Estevez-Abe, Iversen e Soskice, 2001).

Em relação ao papel do Estado, é necessário destacar, em primeiro lugar, que não se trata de um Estado intervencionista, uma vez que incentiva associações e sindicatos a desempenharem funções quase públicas. Diversos mecanismos limitam a possibilidade de intervenção arbitrária. O Banco Central e o Departamento de Cartéis possuem alto grau de autonomia, estando insulados de influência política. Isso confere alto grau de previsibilidade na política monetária e na regulação da concorrência. Em segundo lugar, o sistema político alemão é marcado pela formação de governos de coalizão, dependentes, pois, de soluções de compromisso e avessos a mudanças radicais. Na mesma direção, a existência de um sistema federalista, com vários pontos de veto, torna difícil a ocorrência de rápidas mudanças de direção. E last but not least, muitas atribuições dos grupos sociais são definidas constitucionalmente, dificultando a adoção de mudanças radicais. Em síntese, esses mecanismos, ao evitarem drásticas mudanças de direção, conferem à economia alemã um alto grau de previsibilidade, gerando um contexto favorável para o engajamento das empresas em atividades de longo prazo (Streeck, 1997: 38-39).

Embora não intervencionista, o Estado alemão desempenha papel atuante no funcionamento do modelo. Ele 
provê a estrutura necessária para o sistema de treinamento e para o processo de transferência de tecnologia. Atua, assim, no provimento de educação, na montagem de institutos de pesquisa e seus projetos, sobretudo destinando grande montante de recursos para estas atividades. Outra importante atribuição é desempenhada em nível regional, em que os respectivos governos praticam verdadeira política industrial, incentivando e protegendo as pequenas e médias empresas e canalizando fundos e estímulos para seu funcionamento. Esse comportamento muito contribui para a alta participação das pequenas e médias empresas no capitalismo alemão ${ }^{8}$. E, enfim, por meio de estratégias que se somam à alta regulamentação existente, o Estado protege a indústria nacional contra aquisições indesejadas ${ }^{9}$.

Outra característica central do capitalismo alemão, muito pronunciada até os anos 80 , mas sob fortes mudanças nos dias atuais, é a relação próxima existente entre 30 bancos e empresas, própria da organização econômica alemã, desde o século XIX. Os bancos alemães possuíam ${ }^{10}$ ações das empresas e participavam dos seus conselhos de decisão, que os tornavam, também, menos vulneráveis a aquisições hostis. Este maior envolvimento aumentava a

8. Segundo Schmidt (2002: 128), a ajuda concedida pelo Estado à indústria é três vezes maior na Alemanha que na França e sete vezes maior na Alemanha do que na Grã-Bretanha. A ação dos governos regionais é fundamental para explicar esses números.

9. Apesar das mudanças recentes, que inviabilizaram muitos instrumentos de intervenção, o Estado alemão engaja-se em medidas e negociações para proteger a indústria. Trata-se, pois, de um Estado muito mais ativo que aquele existente no capitalismo liberal. O ponto é bem ilustrado por Coates (2000: 226), que mostra como o Estado americano permitiu passivamente o perecimento da indústria eletrônica de consumo nacional nos anos 80 .

10. Ao contrário da descrição das outras características, utilizo aqui o passado, uma vez que esta relação vem fortemente se alterando. Ainda existe uma relação mais próxima entre bancos e empresas do que no capitalismo liberal, mas a funcionalidade e as implicações dessa relação são muito diferentes do que vigorou até os anos 80 . 
disposição para fornecer recursos de forma mais paciente ${ }^{11}$, enquanto o contato mais próximo atuava como um seguro para as empresas em tempos de crise, reduzindo significativamente o risco e encorajando o investimento. Assim, constituía-se forte diferença em relação ao capitalismo liberal, muito dependente do mercado financeiro e muito sensível à lucratividade de curto prazo ${ }^{12}$. Em síntese, a oferta de capital paciente complementava-se com outras características do funcionamento do modelo, permitindo às firmas conduzir estratégias pacientes de longo prazo, driblando, assim, a necessidade de mudanças imediatas em resposta às flutuações do mercado $^{13}$.

\section{Vantagens comparativas e funcionamento do modelo}

A organização e as formas de coordenação aqui destacadas têm várias conseqüências. Inicialmente, é importante destacar que, em face dos altos salários e da dificuldade de demitir, a possibilidade de competição via preços baixos fica bastante comprometida. Assim, a capacidade de competição desse capitalismo, tão bem evidenciada pela performance exportadora, passa pela competição por diferenciação e pela excelência na produção de bens complexos de alta qualidade. Isso é favorecido pelas relações de trabalho e pelos processos de interação e colaboração já destacados.

A excelência do modelo alemão depende de inovações conduzidas por uma mão-de-obra qualificada e comprome-

11. Dada a maior complexidade assumida pelos setores industriais, é pouco provável que os bancos tenham o expertise necessário para seu monitoramento. Assim, encontravam também no conjunto de networks - compostas por firmas, associações empresariais e institutos de pesquisa, entre outros - as informações e a confiança necessárias para efetivar tal colaboração (Soskice, 1999: 107-109).

12. Até a década de 80 , muitos analistas destacavam esse fator como importante vantagem do capitalismo coordenado em relação ao capitalismo liberal (Coates, 2000).

13. Nos dias atuais, a modificação nessa relação causa apreensões em relação à preservação de outras características do modelo. O ponto é explorado mais adiante. 
tida com a empresa. Nesse processo, é contraproducente e improdutivo o controle estrito por parte dos gerentes. Requer-se, ao contrário, autonomia dos trabalhadores, que acumulam amplo conhecimento do processo e capacidade de resolver os problemas (Soskice, 1999: 115). Assim, é fundamental que a empresa ofereça estímulos para o engajamento do trabalhador. Os altos salários, os mecanismos de participação e a segurança do emprego desempenham essa função, estimulando o investimento em habilidades específicas à firma. Da mesma forma, um sistema de seguro-desemprego generoso garante aos trabalhadores tempo e condições favoráveis para encontrar um emprego compatível com suas qualificações (Estevez-Abe, Iversen e Soskice, 2001). Do ponto de vista da firma, a negociação coletiva, garantindo salários similares para as mesmas categorias, combinada com a ação mediadora das associações, impede a competição por trabalhadores. Isso torna racional 32 também para a firma gastar recursos com a qualificação dos trabalhadores, uma vez que sua própria capacidade competitiva depende disso ${ }^{14}$. Assim, deve-se enfatizar a relevância das relações industriais para o funcionamento do modelo. Ao contrário do ponto enfatizado pelos críticos, que consideram o arranjo fonte de ineficiência e rigidez, as relações industriais funcionam como salvaguardas, reduzindo os custos de transação e incentivando o investimento em habilidades que são críticas para a competitividade da indústria.

14. As firmas têm todo o interesse em manter os trabalhadores, até porque são altos os investimentos em treinamento e o seu custo de reposição. A forte rede de relações, em que as associações desempenham papel central, aumenta a confiança de que a cooperação se efetivará e de que é racional investir nos trabalhadores. Todo esse processo reflete-se em um maior tempo médio no emprego. Em 1990, o tempo médio de permanência no emprego era de 10,4 anos na Alemanha, 7,9 anos no Reino Unido e 6,7 anos nos Estados Unidos. Já a mediana foi de 7,5 anos na Alemanha, 4,4 anos no Reino Unido e três anos nos Estados Unidos (Streeck, 1997: 38). 
Como enfatizado por Soskice (1999) e Hall e Soskice (2001), a estrutura institucional do capitalismo alemão tem fortes implicações em termos de vantagens comparativas. Um arranjo que favorece a cooperação dos trabalhadores e o investimento em habilidades específicas à firma aumenta a capacidade competitiva em produtos de alta qualidade e que dependem de inovações incrementais ${ }^{15}$. Essas vantagens competitivas são também favorecidas por um contexto que garante estabilidade e pela existência das networks supracitadas, favorecendo a troca de informações entre as empresas e entre estas e institutos de pesquisa, agências públicas, fornecedores e clientes.

Como mostram Soskice e Hall (2001), a capacidade competitiva alemã está muito ancorada na sua capacidade de aperfeiçoar bens e tecnologias em setores estabelecidos. Isso faz a Alemanha forte em setores como máquinas-ferramentas, bens de capital, bens duráveis e equipamentos de transporte. Usando dados de Michael Porter(1990), Soskice (1999: 113) mostra que a Alemanha tem vantagem comparativa em 46 nichos da indústria de máquinas, contra 18 do Reino Unido e 17 dos Estados Unidos. O comportamento alemão, no entanto, é muito inferior em setores dependentes de inovações radicais, que demandam respostas rápidas aos sinais de mercado ${ }^{16}$. Assim, o desempenho alemão é fraco em ramos como eletrônica, biotecnologia, novos mate-

15. Ao contrário, países de capitalismo liberal, como os Estados Unidos e o Reino Unido, têm suas vantagens competitivas fundadas na capacidade de inovar radicalmente e de responder rapidamente aos sinais de mercado. A grande autonomia possuída pelos gerentes permite a rápida reorientação das companhias aos sinais de mercado, facilitando a contratação de trabalhadores com habilidades necessárias, a compra de tecnologia adequada e a adaptação aos padrões requeridos (Soskice, 1999: 117). No entanto, estes países tendem a enfrentar dificuldades em setores em que são necessários o engajamento e a cooperação de trabalhadores qualificados.

16. O grande número de stakeholders que participam das decisões das firmas e a forte regulamentação dificultam estas respostas. 
riais e vários ramos do setor serviços (Soskice, 1999: 114). Soskice ilustra bem o ponto mostrando, também com os dados de Porter, o desempenho comparado em nichos do setor serviços. Os Estados Unidos têm capacidade competitiva em 44 nichos; o Reino Unido, em 27; e a Alemanha, apenas em $7{ }^{17}$.

A descrição do capitalismo coordenado implica também em entender as circunstâncias necessárias para que este funcione bem. O bom funcionamento do modelo alemão, com sua forte regulamentação e altos salários, depende da capacidade de se manter competitivo em nichos de alta qualidade e alto valor agregado. É isso que permite o emprego de trabalhadores qualificados e o pagamento de salários elevados, além de outros benefícios. Uma vez que a capacidade competitiva seja perdida, toda a estrutura do sistema ameaça ruir. Com altos níveis de desemprego, não apenas a coesão entre os trabalhadores fica prejudicada, 34 mas os gastos com o Welfare State tendem a ficar insustentáveis (Streeck, 1997: 42-43).

\section{Dificuldades a partir dos anos 70}

Foi a incapacidade de manter a liderança nos nichos cativos de alta qualidade que trouxe os problemas a partir dos anos 70, quando a Alemanha passou a sofrer o acirramento da competição japonesa. Produzindo a custos muito mais baixos, propiciados pela eficiência de seu modelo de organização da produção, os japoneses tomaram vários mercados. Em tal situação, os limites do sistema de inovação alemão ficaram claros: muito bom em inovações incrementais, o

17. Assim, vale notar a complementaridade entre as capacidades inovativas nos dois tipos de modelos de capitalismo. Esse é um ponto também destacado por Boyer (2003: 172), segundo o qual o padrão de inovações alemão nos anos 80 foi um espelho do padrão americano, forte em engenharia civil, máquinas agrícolas, equipamentos e máquinas ferramentas e fraco em tecnologia da informação, semicondutores, biotecnologia e novos materiais, setores em que os Estados Unidos são fortes. 
modelo mostrou fortes dificuldades em enfrentar um contexto diferente, caracterizado pelo acirramento da competição e por mercados mais instáveis (Streeck, 1997).

Durante os anos 70 e 80, o arranjo corporativo permitiu uma resposta mais orquestrada à crise, refletindo-se em resultados macroeconômicos melhores que nos países do capitalismo liberal. Nos anos 80, o câmbio favorável e a boa performance exportadora adiaram a realização de reformas. No entanto, a unificação alemã agravou drasticamente o quadro. Como enfatiza Streeck (1997: 47), embora as dificuldades indicassem limites internos ao modelo, a unificação foi um choque tão grave que já seria por si só capaz de comprometer o arranjo. A transposição das instituições ocidentais para o Leste, única condição para conservar o modelo ${ }^{18}$, trouxe fortes conseqüências. A transposição do Welfare State para o Leste, aliada ao forte aumento do desemprego, elevou consideravelmente o déficit público. Uma economia que já enfrentava dificuldades para gerar mercados capazes de manter empregados os trabalhadores do lado ocidental teve o desafio consideravelmente inflado, tornando-se inatingível.

Em tal contexto, as políticas de treinamento tiveram pouco resultado. $\mathrm{O}$ governo alemão tentou reagir adotando políticas como redução da idade de aposentadoria e redução da jornada de trabalho. Mesmo que no curto prazo os resultados tenham sido favoráveis, a inviabilidade de tais políticas logo se mostrou patente. As dificuldades foram também amplificadas com a forte enxurrada de trabalhadores do Leste europeu, muito baratos e com certo grau de qualificação. Em tal contexto, aumentava a tentação para os empresários abandonarem o arranjo, aproveitando as vantagens propiciadas pela abundância de mão-de-obra barata (Streeck, 1997: 50).

18. Em caso contrário, a contratação de trabalhadores muito baratos do Leste inviabilizaria o sistema de relações de trabalho. 
Assim revela-se, desde os anos 70, a falta de uma resposta articulada aos novos desafios. Durante muito tempo, os alemães acreditavam que não precisavam competir por preços, dada a tradição e a qualidade de seus produtos. Assim, negligenciaram inovações importantes, sendo muito lentos para introduzir, por exemplo, práticas ligadas à produção enxuta. Negligenciaram que existia uma mudança muito mais séria na fase do capitalismo, que incluía mudanças no paradigma produtivo-tecnológico.

Durante o governo Kohl, a preocupação ficou centrada no controle do déficit público, nos efeitos da unificação e na introdução do euro, além de questões eleitorais. Pouco foi feito em direção a uma rearticulação do modelo. O governo Schröeder demonstrou, desde o início, sensibilidade às dificuldades, atestada pela intenção de reduzir o déficit público e os impostos, condição para estimular o investimento privado e a competitividade. Mas logo percebeu as dificul36 dades para conciliar tais medidas com as demandas da ala esquerda do partido (Yamamura, 2003: 140-141).

\section{Ameaças ao modelo socialmente regulado}

Não foram apenas o acirramento da competição internacional e as características do sistema de inovação que trouxeram dificuldades ao modelo alemão. $\mathrm{O}$ mundo mudou significativamente a partir dos anos 70. A rápida integração comercial e financeira, aliada à mudança no regime de câmbio e à desregulamentação financeira, reduziu significativamente a capacidade dos governos de protegerem setores da economia. Em um contexto de internacionalização produtiva e financeira, tornou-se muito mais difícil a preservação de um modelo, cuja coordenação passava por formas alternativas ao mercado.

Assim, a relação de longo prazo existente entre bancos e empresas foi afetada. Em face das novas oportunidades abertas pela desregulamentação financeira, os bancos sen- 
tiram-se atraídos pelo cassino global, reduzindo o interesse na colaboração estreita com as empresas. Na mesma direção, as grandes firmas tiveram acesso a fontes alternativas de financiamento, facilitadas pelas diversas inovações financeiras, o que também reduziu seu interesse em conservar uma relação muito próxima com os bancos.

Pressões por mudanças vêm partindo também das grandes empresas internacionais, que passaram a atuar em contextos nacionais diversos e a demandar um padrão de regulação mais homogêneo, isto é, com baixa regulação. A atuação em bolsas de valores internacionais, que demandam certos padrões de governança empresarial, também segue nessa direção. A internacionalização, aprofundada também com a integração européia, aumenta o interesse das empresas de atuarem internacionalmente, ao mesmo tempo em que o desejo de atrair capital pressiona os governos a adotar modos de regulação mais favoráveis ao capital (Hall, 1999: 154). Ao mesmo tempo, o processo de integração européia pressiona por mecanismos de regulação que possam mais facilmente ser compartilhados por seus membros.

Algumas mudanças dizem respeito aos trabalhadores e às relações industriais. Mudanças recentes vêm enfraquecendo os trabalhadores, ocasionando, em certos países, reformas favoráveis ao capital. Em primeiro lugar, o forte aumento do desemprego tem reduzido o poder de barganha dos trabalhadores; em segundo lugar, uma mudança no perfil de emprego - com o forte crescimento do emprego no setor serviços e no setor público - tem reduzido a coesão dos sindicatos e enfraquecido os trabalhadores industriais; e, em terceiro lugar, a intensa integração produtiva, dando aos empresários a opção de migrar em direção a contextos menos regulamentados, estaria reduzindo a capacidade de barganha dos sindicatos (Hall, 1999). Apesar dessas pressões, muitos países, incluindo a Alemanha, vêm preservando suas relações de trabalho. A influência dos sindicatos, a regulamentação de seu 
mercado de trabalho e a cobertura das negociações coletivas continuam elevadas (Golden, Wallerstein e Lange, 1999).

Enfim, uma importante fonte de pressão veio da mudança no paradigma produtivo-tecnológico. Segundo Yamamura (2003), o capitalismo se encontra hoje na fase inicial de um terceiro paradigma produtivo tecnológico, centrado na tecnologia da informação. À semelhança dos dois paradigmas anteriores, centrados respectivamente no vapor-siderurgia e na eletricidade-automóvel, essa primeira fase é marcada por novas oportunidades de investimento, muitas inovações e fortes mudanças nos preços relativos. Trata-se, pois, de uma fase que tende a favorecer os países com baixa regulamentação, alta capacidade de implementar mudanças e agilidade em levantar capital. Nesse contexto, países com alta regulamentação e baixa capacidade de resposta levam desvantagem ${ }^{19}$.

No contexto atual, características que eram vantagens 38 do modelo alemão perdem importância, transformandose, eventualmente, em desvantagens. As vantagens de um capital paciente, louvadas até há pouco tempo por analistas em todo o mundo, vêm perdendo importância. Ao contrário, o sistema financeiro alemão vem sendo criticado pela falta de agilidade, pela incapacidade de levantar capital rapidamente e pela relutância em se envolver em negócios de alto risco.

Assim, por vários focos diferentes, as instituições alemãs estão sob pressão. Precisam de reformas, a fim de aumentar a flexibilidade e responder ao novo contexto. O processo de mudança institucional é complexo, em face dos vários inte-

19. Segundo Yamamura (2003), o consolo a favor da Alemanha é que também o paradigma atual tende a se estabilizar, embora o autor acredite que tenda a demorar mais tempo que nos paradigmas anteriores. Atingindo-se essa segunda fase, os países com alta capacidade organizacional e excelência em inovações incrementais tendem a levar vantagem, como teria sido atestado pela última década do padrão fordista. 
resses cristalizados em favor das instituições vigentes (Vogel, 2003; Guimarães, 2005). No entanto, reformar é fundamental para preservar a capacidade econômica do modelo, sob o risco, até mesmo, de inviabilizar o pacto social. Yamamura (2003) enfatiza que o ideal seria reformar conservando a capacidade organizacional do modelo, que já mostrou bons resultados no passado e tende a aumentar em importância na fase subseqüente do paradigma.

\section{A persistência das relações de trabalho}

Um ponto muito sensível do debate vem ocorrendo em relação às instituições trabalhistas, uma vez que a negociação coletiva, a proteção ao emprego e a participação dos trabalhadores nas decisões das empresas são características centrais do capitalismo coordenado alemão. O que vem se notando nessa área, ao contrário do que ocorreu nos países de capitalismo liberal, é que não está ocorrendo desregulamentação do mercado de trabalho. Algumas medidas têm sido adotadas para aumentar a flexibilidade, mas o arranjo continua intacto.

A partir dos anos 90, a pressão por mudanças tem aumentado, sobretudo as demandas para transferir as negociações para o nível da firma, de forma a levar em conta as particularidades de cada empresa. Estas partem, basicamente, das pequenas e médias empresas, que, apresentando dificuldades para cumprir as determinações da negociação coletiva, acusam as associações empresariais de representarem os interesses das grandes empresas ${ }^{20}$. A dificuldade em cumprir os acordos foi particularmente forte na parte Leste, levando muitas empresas a não se filiarem à associação. Em

\footnotetext{
20. Thelen e Kume (2003) enfatizam que a variável singular mais importante para explicar a divisão é o tamanho das empresas. Segundo Thelen e Kume (2003: 201), a cobertura das negociações coletivas no Oeste aumenta de $35,7 \%$, quando se consideram firmas com até 4 empregados, para 75,8\% em firmas com mais de 1.000 empregados.
} 
survey de 1997, apenas 25,7\% das firmas do Leste, empregando $43,9 \%$ dos trabalhadores da indústria, pertenciam às respectivas associações (Thelen e Kume, 2003: 187). Mas a redução na filiação também vem ocorrendo na parte Oeste. Entre 1995 e 1997, a percentagem de empresas filiadas reduziu de $51,8 \%$ para $49 \%$ das firmas, cobrindo $65,3 \%$ do total de trabalhadores. Os números dos trabalhadores da indústria mecânica, setor industrial importante e com forte representação trabalhista, são bastante significativos: em 1984, antes da unificação, $75 \%$ das empresas estavam filiadas à associação; em 1994, esse número caiu para $65 \%{ }^{21}$.

No entanto, apesar da queda na filiação, é errado concluir que existe uma pressão geral por descentralização. É grande o número de empresários que não abraçam a proposta, uma vez que preferem a negociação centralizada a terem de enfrentar os trabalhadores separadamente. Os empresários temem um grande fortalecimento dos conse40 lhos de trabalho, a ameaça de interferência legislativa, o aumento excessivo de salários em períodos de prosperidade, a interferência de uma parte externa para arbitrar o conflito, que elevaria significativamente os custos de transação, e o recurso a processos jurídicos, que inviabilizaria o planejamento (Thelen e Kume, 2003: 199).

Thelen e Kume (2003: 197-198), aliás, trazem interessantes exemplos de tentativas por parte de uma associação empresarial e de uma firma de impor concessões aos trabalhadores. Nesses eventos, ficaram evidentes dois importantes aspectos: a falta de unidade entre os empresários; e a relutância em abandonar a negociação coletiva. Em um

\footnotetext{
21. Um problema relacionado é o aumento do número de firmas que não cumprem o estipulado pelos acordos coletivos. Assim, receosos de demissões, os conselhos de trabalho aceitam salários mais baixos e menos direitos. Segundo survey citado por Thelen e Kume (2003: 188), em 15,6\% das firmas do Oeste e 29,8\% da firmas no Leste os conselhos de trabalho estariam burlando decisões determinadas coletivamente.
} 
primeiro exemplo, uma associação empresarial na Bavária, controlada por pequenas e médias firmas, procurou impor aos trabalhadores maior flexibilização. Estes reagiram com uma greve, o que acarretou divisão entre os empresários, acirramento das críticas em relação à linha dura adotada pela associação e ameaças de acordo em separado com o sindicato. Esse quadro levou a um recuo da associação, que, até, concedeu aumento de salários aos trabalhadores. Em um segundo exemplo, a Daimler, respaldada por uma ofensiva da associação empresarial e pela legislação do governo, tomou a liderança, anunciando a redução do valor do auxílio-doença. A iniciativa, no entanto, não foi seguida por outras firmas. Em face do protesto dos trabalhadores, a BMW, que detinha uma longa lista de encomendas e não queria uma paralisação, rapidamente recuou. Posteriormente, ambas as empresas insistiram na necessidade de a negociação ser conduzida em nível central (Thelen e Kume, 2003: 198).

Assim, Thelen e Kume mostram que a tese de convergência em direção à desregulamentação das relações de trabalho e à descentralização da barganha salarial não se verifica no caso alemão. Embora venham ocorrendo medidas na direção de tornar o modelo mais flexível, as instituições têm se conservado, o que é explicado não apenas pela força dos trabalhadores, mas também pelo interesse dos empresários em conservar o arranjo. Do ponto de vista dos representantes empresariais, que têm, portanto, acesso a decisões, conservar essas networks é fundamental para preservar a sua posição, o acesso a recursos e o poder. Por sua vez, também os empresários, cuja capacidade competitiva depende do arranjo, não têm interesse em abandoná-lo. O interesse de manter a estabilidade e a paz no chão da fábrica é ainda maior quando se consideram o acirramento da competição e a adoção de muitas práticas ligadas à produção enxuta, como o sistema just in time. 
Outro ponto importante é que as dificuldades vêm surgindo não pela fraqueza dos sindicatos, mas pela divisão entre os empregadores, como indicado pela redução do número das empresas filiadas às associações. Isso é percebido com preocupação pelos sindicatos, que sabem que o funcionamento do arranjo depende de parceiros fortes. Receiam, assim, que uma queda no número de empresas dispostas a pagar para terem relações estáveis e cooperativas possa inviabilizar o arranjo ${ }^{22}$. Em síntese, embora as relações de trabalho venham sendo conservadas no centro do sistema, o número de empresas que as adotam vem caindo, gerando uma redução que pode, no futuro, pôr em risco seu funcionamento (Thelen e Kume, 2003: 200).

\section{Mudanças no modelo de produção}

Na segunda metade dos anos 70, o modelo de produção alemão estava ainda muito orientado para práticas fordistas, 42 embora fosse menos dependente de economias de escala e a estrutura empresarial fosse menos concentrada do que nos Estados Unidos. A performance era regulada por práticas tayloristas, combinadas com pagamento por resultados. Em relação à supervisão da fábrica, a influência dos engenheiros especialistas era muito elevada. Nesse ponto, é importante destacar que o modelo era muito dependente de engenheiros e de peritos, cuja influência era também muito grande em relação à inovação e à melhoria do processo (Jürgens, 2003: 218-219) ${ }^{23}$.

22. O funcionamento do arranjo depende da capacidade empresarial, relacionada à força das associações. Uma vez que as associações se enfraqueçam, a importância dos sindicatos como parceiros tende também a reduzir. Isso é bem ilustrado pelas economias do capitalismo liberal, que, na inexistência de capacidade empresarial, optaram por enfraquecer os sindicatos.

23. Segundo Streeck (1997: 40), a grande incidência de engenheiros como gerentes era um ponto adicional favorável, fazendo com que as relações de autoridade no chão da fábrica fossem respaldadas pelo maior conhecimento técnico. 
A particularidade do modelo alemão se revelava nas relações industriais, marcadas por vários mecanismos de participação dos trabalhadores. Esses eram consultados quando da introdução de novas tecnologias, o que era feito de forma a não causar redundâncias. Além disso, a política de recursos humanos e a forte ênfase no treinamento vocacional distinguiam o modelo alemão, dada a importância conferida ao aumento da qualificação dos trabalhadores, tanto os de colarinho branco como aqueles diretamente envolvidos na produção.

A partir dos anos 70, várias iniciativas, conduzidas mediante a colaboração entre trabalhadores e empresários, foram adotadas visando tornar o modelo mais flexível. Os trabalhadores aceitaram introduzir novas tecnologias e maior flexibilidade ao modelo, em troca de segurança no emprego e treinamento em novas qualificações. Essas reformas produziram bons resultados, contribuindo para a performance favorável da indústria nos anos 80. Por meio do desenvolvimento de estruturas de trabalho inteligente, as vantagens alemãs em alguns nichos de alta qualidade foram reforçadas. Naquele momento, a qualidade e a reputação dos produtos permitiam que eles fossem vendidos a preços mais elevados. Isso valia não apenas para automóveis e máquinas-ferramentas, exemplos clássicos da excelência da produção alemã, mas também em outros ramos, como engenharia de precisão e têxteis (Jürgens, 2003: 220-221).

Entretanto, os alemães foram lentos em introduzir práticas como produção em equipe, integração entre fornecedores e clientes, e reorganização do projeto. Isto, segundo Jürgens (2003), tornou o processo de produção excessivamente complexo e dependente de engenheiros e peritos. Consolidou-se, assim, uma fonte de rigidez e de aumento dos custos, não compensada pela alta produtividade dos trabalhadores alemães. O ciclo virtuoso transformou-se em vicioso, favorecendo a reestruturação do modelo produtivo nos anos 90 . 
A introdução das práticas ligadas à produção enxuta foi feita de forma gradual, inicialmente conciliada com as práticas anteriores. No entanto, foram consideráveis as mudanças na organização da produção, no controle do processo e no desenho de emprego. Práticas como qualidade total, just in time e melhoria contínua foram implantadas. $\mathrm{O}$ trabalho em equipe foi valorizado, aumentando a responsabilidade dos trabalhadores e revertendo a separação tradicional entre produção, inspeção da qualidade e reparo (Jürgens, 2003: 228). No entanto, conservou-se a posição dominante dos experts na etapa de aperfeiçoamento do processo.

Assim, os anos 90 foram marcados pela disseminação das práticas de produção enxuta, tornando os modelos de produção nacionais menos diferentes. A introdução dessas práticas teve efeitos muito positivos sobre a competitividade da indústria alemã, que procurou também, por meio da constituição de redes com fornecedores do Leste europeu, 44 perseguir mais veementemente estratégias de redução de custos. No entanto, há evidências de que a diferença também se reduziu no que tange à qualidade dos produtos. Segundo Jürgens (2003: 233), a conclusão extraída por surveys de qualidade indica que a diferença entre as principais companhias tem se tornado muito pequena e que as firmas alemãs não se encontram necessariamente na frente.

Em todo esse processo, o que permanece distintivo no modelo alemão é a política de recursos humanos e as relações industriais. Como enfatizado, a introdução de tecnologias e de práticas organizacionais vem sendo conduzida em colaboração com os trabalhadores e compatibilizada com a manutenção do emprego (Jürgens, 2003: 229). São comuns as concessões feitas pelos trabalhadores no intuito de preservar as plantas. Nesse processo, as instituições de negociação coletiva têm demonstrado grande capacidade de adaptação. Nos últimos anos, mudanças vêm sendo feitas para transferir algumas decisões para as plantas, no intuito de 
aumentar a flexibilidade. Da mesma forma, os empresários obtiveram ganhos na direção de reduzir a participação dos trabalhadores nas decisões ${ }^{24}$. Não obstante essas mudanças, o core do sistema de relações industriais mantém-se intacto.

\section{Mudanças, mas também conservação}

Apesar de uma série de mudanças em curso, o modelo alemão continua distintivo. Embora isso se pronuncie mais fortemente no que tange às relações industriais, a diferença é também pronunciada em outras esferas. Na área financeira, as modificações recentes foram muito significativas, com a forte redução no vínculo entre bancos e empresas. Os bancos vêm se reestruturando nos moldes de bancos de investimento, e a redução de sua influência nas empresas se manifesta em relação tanto à posse de ações como aos assentos nos conselhos diretivos das mesmas. A despeito disso, é necessário não exagerar a convergência em direção a um modelo liberal. Os bancos ainda têm influência, e as grandes empresas, embora menos dependentes de empréstimos bancários, ainda têm uma dependência limitada em relação ao mercado financeiro. A participação do capital estável e comprometido com a empresa é ainda muito grande, e, portanto, a pulverização da posse e o número de investidores orientados financeiramente são limitados. Os elementos de conservação estão também muito presentes em relação às pequenas e médias empresas, ainda muito dependentes de empréstimos bancários fornecidos pelos bancos regionais (Jackson, 2003).

Em relação à governança corporativa, reformas vêm sendo feitas para aumentar a transparência das empresas.

24. Em 2004, travou-se ampla ofensiva com o objetivo de reduzir a representação trabalhista nos conselhos de direção das grandes empresas, acabando com a paridade entre trabalhadores e gerentes. A medida foi defendida pelos empresários como necessária para a obtenção de um modelo de governança corporativa mais moderno e flexível. A resistência dos trabalhadores e dos segmentos mais à esquerda da coalizão, no entanto, foi considerável. 
Tanto as agências regulatórias quanto os auditores tornaram-se mais independentes. Tem-se adotado uma nova cultura de administração, favorável a aumentar a influência do acionista. Os salários dos gerentes têm aumentado, mas a distância em relação à remuneração recebida por executivos nos Estados Unidos continua muito elevada. A introdução de stock options tem também sido lenta (Jackson, 2003).

Enfim, as fusões e aquisições ainda têm papel limitado na economia alemã, sendo sua participação na economia muito inferior à verificada nos Estados Unidos e no Reino Unido $^{25}$. Vários mecanismos protegem as empresas contra aquisições hostis, incluindo a participação das associações no monitoramento, o papel dos bancos nos conselhos das empresas, os mecanismos de participação dos trabalhadores e, mesmo, a ação do Estado. Além disso, como aponta Schmidt (2002: 119), a economia alemã estava muito menos internacionalizada do que outras economias européias. Em 46 1998, o fluxo de investimentos externos para a Grã-Bretanha, como percentagem do PIB, foi quatro vezes superior àquele recebido pela Alemanha. Da mesma forma, o fluxo de investimentos britânicos para o exterior foi três vezes superior ao alemão.

Schmidt (2002: 127-130), efetuando comparações com a França e a Grã-Bretanha, destaca algumas particularidades do capitalismo alemão. Na maior parte das comparações, Schmidt mostra que a Alemanha e a Grã-Bretanha situam-se em extremos opostos, com a França ocupando posição intermediária. Em relação à qualidade do produto e ao grau de qualificação da mão-de-obra, a Alemanha leva forte vantagem em relação à Grã-Bretanha. Quanto à produtividade, a Alemanha também supera amplamente a

25. Segundo Schmidt (2002: 119), o valor das fusões e aquisições como percentagem do PIB foi, em 1999, duas vezes inferior na Alemanha quando comparada com a Grã-Bretanha. 
Grã-Bretanha, embora tenha registrado números inferiores à França, que vem passando por forte reestruturação. A Alemanha também supera os outros dois países no que tange às taxas de investimento. Sobre os indicadores sociais, as vantagens em relação à Grã-Bretanha são claras, como ilustrado pela melhor distribuição de renda e pelas menores taxas de pobreza. No entanto, a Alemanha apresentou desempenho inferior ao Reino Unido no que se refere às taxas de desemprego, aos custos do trabalho e ao red tape, uma vez que a burocracia e o tempo gasto para se abrir uma empresa são muito maiores na Alemanha. Os britânicos também detinham claras vantagens no que tange à geração de um ambiente mais favorável à criatividade e à inovação, principalmente em setores novos e em rápida mudança.

Um ponto muito sensível diz respeito à capacidade de competição da Alemanha em setores ligados à ciência básica e aplicada. Embora não sejam essas as únicas fontes de inovação, sua importância tem aumentado em face do paradigma produtivo-tecnológico atual ${ }^{26}$. A Alemanha tem um bom sistema de ciência e tecnologia e uma boa estrutura de pesquisa. Boyer (2003) encontra evidências de que esse país, em termos do número de patentes por pessoal empregado em pesquisa e desenvolvimento (P\&D), estaria superando o Reino Unido e a França. Em relação à evolução recente, Boyer enfatiza que o sistema de $\mathrm{P} \& \mathrm{D}$ alemão permaneceu constante ou, mesmo, melhorou no mercado de patentes europeu. No entanto, quando avaliado a partir do mercado americano, nota-se forte redução da eficiência do sistema

26. Entre os exemplos de fontes alternativas de inovações, destacam-se a trajetória natural ao setor, a relação com clientes e fornecedores, a relação com institutos de pesquisa, a introdução de novos materiais e as inovações incrementais feitas na própria firma. Boyer (2003), enfocando por um outro ângulo, destaca três fontes básicas de inovação: aquelas advindas da maior divisão do trabalho e especialização, as inovações realizadas no chão da fábrica e as inovações advindas de fontes científicas e colaboração com laboratórios. A Alemanha, segundo Boyer, teria bons resultados nas duas primeiras, mas estaria atrasada em relação à última. 
de P\&D alemão (Boyer, 2003: 167). A principal defasagem, no entanto, encontra-se em relação à pesquisa acadêmica, como atestado pelos resultados em nível tanto de publicações como de citações, em que é grande o atraso em relação aos Estados Unidos e ao Reino Unido. A produtividade da pesquisa básica, embora acima do Japão e no mesmo nível da França, está também significativamente atrás dos Estados Unidos e do Reino Unido (Boyer, 2003: 156)

Assim, a Alemanha tende a enfrentar fortes desafios, principalmente se o paradigma atual continuar muito centrado em inovações originadas da pesquisa básica. A isto se soma a necessidade de reforçar os incentivos à criatividade e à inventividade, de se tornar mais ágil em alguns setores e de aumentar a capacidade de responder aos desafios e oportunidades.

\section{Respostas recentes do governo alemão - a Agenda $2010^{27}$}

Em face dos resultados econômicos desfavoráveis, que incluem baixa taxa de crescimento e altas taxas de desemprego $^{28}$, o governo alemão vem-se engajando em um amplo esforço para reduzir os custos do Welfare State, criar empregos e tornar o modelo econômico mais dinâmico e flexível. As medidas, bem sintetizadas na Agenda 2010, incluem significativa redução na carga tributária e amplas reformas no Welfare State. O governo vem reduzindo os gastos no sistema de saúde e reformando o sistema de seguridade social, na direção de torná-lo sustentável ${ }^{29}$. Outra linha anunciada na Agenda 2010 é a redução dos benefícios e do prazo de recebimento do seguro-desemprego, adotando penalidades

27. Esta seção está baseada no pronunciamento de Schröeder e no artigo One Year of Agenda 2010, citados no final do artigo.

28. O desemprego, que se situava em 200 mil nos anos 70, atingiu 5 milhões de pessoas em 2005.

29. O governo propõe aumento na idade de aposentadoria, revertendo as medidas adotadas nos anos 80 e 90 . 
para aqueles que recusem uma oferta de emprego. Assim, aumenta-se a pressão para os desempregados aceitarem emprego, mesmo quando não correspondente à sua formação profissional, o que constitui uma forma de acelerar a re-introdução no mercado de trabalho.

Um ponto nevrálgico das reformas centra-se na tentativa de reduzir os custos e de conferir maior flexibilidade ao mercado de trabalho, medidas consideradas fundamentais para aumentar a capacidade da economia de absorver os desempregados, principalmente os menores de 25 anos. Forte ênfase vem sendo dada à redução dos gastos das empresas com encargos trabalhistas e à redução da proteção contra demissões. Em medida aprovada recentemente, os trabalhadores empregados a partir de 10/10/2004 em empresas com menos de 10 trabalhadores não serão incluídos na legislação que garante proteção ao emprego ${ }^{30}$. Abre-se também oportunidade para contratos de trabalho por tempo determinado, sem proteção ao emprego. Na mesma linha, o governo retira a proibição de demissão para maiores de 50 anos, procurando eliminar o desincentivo para a contratação de indivíduos nessa faixa etária. E last but not least, procura-se estimular empregos em tempo parcial e com baixos salários ${ }^{31}$.

Todo esse esforço vem sendo defendido em conjunto com um forte programa de treinamento, considerado fundamental para inserir as pessoas no mercado de trabalho. Uma mesma preocupação é demonstrada em relação ao sistema de pesquisa e desenvolvimento e aos gastos com educação. Embora reconheça que gaste mais nessas áreas que a média da Europa, o governo enfatiza que a Alemanha precisa concentrar os esforços e aumentar investimentos, melhorando

30. Anteriormente, essa lei só era válida em empresas com até cinco empregados. 31. Em síntese, o governo vem procurando, ao aumentar a flexibilidade e reduzir custos e obstáculos, incentivar as contratações, permitindo, principalmente as empresas menores, a contratar e demitir de acordo com o ciclo de negócios. 
seu sistema de inovação. Reitera, também, que as reformas no Welfare State permitirão a canalização de recursos para investimentos nessa área. E, enfim, enfatiza o compromisso de reduzir o red tape, tornando muito mais simples e rápida a abertura de empresas, medida inserida em um esforço maior para tornar o país mais atrativo para investimentos.

Em síntese, o governo vem adotando medidas que, no intuito de tornar a economia mais flexível e de estimular o emprego, alteram regras que marcavam o modelo anterior. No entanto, tanto o Welfare State quanto os direitos trabalhistas continuam muito mais abrangentes que nos países de capitalismo liberal. O cerne do sistema de relações industriais continua intacto. As medidas de flexibilização do emprego são bem restritas, abrangendo, como enfatizado, apenas postos bem específicos. Aos demais, preserva-se a forte regulamentação, com todas as implicações destacadas acima. As mudanças devem, pois, ser entendidas como 50 iniciativas para tornar o modelo mais flexível, configurando-se como uma resposta aos desafios econômicos recentes. Mas são adotadas no intuito de preservar traços centrais do modelo de capitalismo social existente no país.

\section{Conclusão: enfrentando o desafio}

Os resultados alcançados pela Alemanha nas últimas cinco décadas têm implicações importantes. Mostram que é possível uma economia ser altamente competitiva e bem-sucedida pagando altos salários e tendo relações de emprego mais estáveis, uma distribuição de renda mais igualitária e um abrangente Welfare State. Demonstra que sindicatos fortes não são incompatíveis com boa performance econômica e que uma série de networks, fornecendo mecanismos de regulação que complementam o mercado, são capazes de gerar bom desempenho competitivo em vários setores.

Apesar de todos esses resultados, o modelo de capitalismo coordenado encontra-se sob pressão. Tem procurado 
se adaptar reduzindo os custos e aumentando a flexibilidade, mas preservando traços centrais do arranjo. As relações de trabalho continuam firmes e as mudanças recentes, incluindo as propostas pela Agenda 2010, não põem em risco os fundamentos do arranjo. A apreensão, no entanto, surge quando se considera a complementaridade entre as partes do modelo. A existência de estratégias pacientes e de longo prazo estava, como visto, respaldada em relações próximas e de longo prazo entre bancos e empresas. Assim, pergunta-se se um sistema financeiro mais direcionado para o mercado não colocaria em risco relações de trabalho de longo prazo. Em outras palavras, questiona-se se as mudanças em curso, incluindo a intensificação da internacionalização da produção, o rápido crescimento de um mercado secundário, o aumento de fusões e o maior poder do acionista, não viriam, no futuro, a inviabilizar os mecanismos de proteção ao emprego e os canais de participação dos trabalhadores. Assim, os riscos de descaracterização do modelo existem, da mesma forma que existem também interesses e razões para a conservação de muitas instituições. As próprias reformas vêm sendo conduzidas com o intuito de preservar os pontos positivos de um capitalismo socialmente coordenado.

Os desafios são reais, e as mudanças são centrais para que a Alemanha não fique para trás. Existem muitos interesses em favor das instituições atuais, mas a nova realidade do sistema econômico mundial demanda várias mudanças. A opção é responder ou perecer. No entanto, responder não implica desregulamentar as instituições e se transformar em um capitalismo de mercado liberal. Como outras experiências internacionais apontam, incluindo exemplos da Holanda e de países Escandinavos, é possível fazer o ajuste preservando relações mais próximas entre bancos e empresas, relações cooperativas entre trabalhadores e gerentes e várias formas de regulação via networks. 
Os alemães sabem que seu modelo tem vantagens, como atestado pela liderança e excelência em vários setores. Reconhecem que a liderança está ligada a suas instituições e são céticos em relação às receitas de simples abandono do arranjo. Aos analistas que pregam uma cópia do modelo americano, escapa o fato de que esses avanços foram obtidos à custa de deterioração na distribuição de renda, redução dos salários, aumento da pobreza e precarização nas relações de trabalho. Em face da ameaça sempre presente de fusões e aquisições, aumenta-se o risco de demissões e redundância no emprego. É cada vez menor o número de pessoas que podem contar com uma carreira estável.

Assim, como enfatiza Yamamura (2003), aproximar de um modelo liberal aumentaria a agilidade e permitiria responder prontamente aos sinais de mercado, mas destruiria uma estrutura organizacional que pode ser útil no futuro, além de abandonar os mecanismos de cidadania social e os 52 resultados muito mais favoráveis em termos sociais. O ideal para a Alemanha seria obter um consenso capaz de guiar o delicado e complexo processo de mudança institucional, fazendo as mudanças necessárias, mas preservando os elementos mais caros ao modelo.

Os resultados da eleição de setembro de 2005, marcada pelo forte equilíbrio entre os dois principais partidos - o CDU/CSU, de Angela Merkel, e o SPD, de Schröeder -, retratam muito bem as difíceis escolhas e o impasse que o modelo alemão vem enfrentando. Os alemães reconhecem a necessidade de reformas, mas valorizam também os benefícios e direitos do modelo de capitalismo social, não comprando acriticamente as promessas do receituário liberal. O impasse, que se traduziu na incapacidade de uma das partes formar uma coalizão majoritária com partidos mais afins, levou à formação de uma grande coalizão entre os dois partidos, fato que havia ocorrido apenas uma vez após a Segunda Guerra Mundial. 
A Grande Coalizão amplifica as dificuldades para a aprovação de reformas polêmicas. A grande abrangência e heterogeneidade de posições, já presente dentro de cada partido, torna-se amplificada por uma coalizão que inclui desde segmentos da extrema direita até os grupos mais à esquerda, fortes opositores das reformas propostas por Schröeder. As dificuldades são ainda aumentadas pelos pontos de veto adicionais introduzidos pelo sistema federalista, que se traduzem na oposição de certas lideranças regionais ao programa de reformas.

Há evidências, no entanto, de que a grande coalizão terá sucesso na aprovação de algumas medidas, uma vez que são em grande parte compartilhadas. Uma grande ênfase será dada à redução do déficit público, adequando-o aos níveis exigidos pela União Européia. Há também certo consenso sobre a necessidade de reformas no sistema de saúde, no sistema previdenciário e no sistema tributário. Tanto Merkel quanto Schröeder concordaram, em 2005, quanto à necessidade de redução nos impostos pagos pelas empresas, devendo também haver uma redução nos encargos trabalhistas. Há também boas perspectivas para uma reforma no sistema federalista, além do consenso em relação à necessidade de ampliar os gastos em Pesquisa e Desenvolvimento, embora não necessariamente em como financiá-los. Dificuldades inextricáveis devem, no entanto, marcar as tentativas de reforma no mercado de trabalho. As propostas de desregulamentação feitas por Merkel serão fortemente combatidas por segmentos do SPD, que acreditam que a Agenda 2010 já foi longe demais. Assim, a Alemanha deve conservar seu sistema de relações de trabalho, preservando a forte proteção ao emprego e os mecanismos de participação dos trabalhadores.

Alguns resultados positivos marcaram a economia alemã em 2005. As exportações tiveram bom comportamento e há evidências de forte redução dos custos pelas corpora- 
ções. Evidências do último mês de dezembro indicam uma recuperação surpreendente dos gastos dos consumidores, que, dissociada de qualquer bolha especulativa ou imobiliária, tende pois a ser consistente. Além disso, deve-se destacar que uma dificuldade crítica relaciona-se à política monetária muito restritiva praticada pela União Européia, que valoriza o câmbio e impacta negativamente as exportações. Nessa direção, uma política menos restritiva tende a trazer um maior vigor para a economia, permitindo ganhos no combate ao desemprego e maior fôlego para enfrentar importantes desafios. Estes incluem, principalmente, a necessidade de reforçar o sistema de inovações, particularmente no que tange à pesquisa básica e à capacidade de inovar radicalmente. Outro desafio crítico diz respeito ao aumento da agilidade de resposta de alguns setores, particularmente aqueles mais ligados ao novo paradigma produtivo, incluindo vários nichos do setor serviços. Estas mudanças, críticas para o dinamismo da 54 economia, tendem a se fazer decisivas para a preservação de algumas das características mais caras do modelo de capitalismo coordenado, incluindo sua grande capacidade organizacional e seus bons resultados distributivos e sociais.

\section{Alexandre Queiroz Guimarães}

é professor do Departamento de Relações Internacionais e do Departamento de Economia da PUC-MG

\section{Referências bibliográficas}

BOYER, Robert. "The embedded innovation systems of Germany and Japan: Distinctive features and futures". In: YAMAMURA, Kozo e STREECK, Wolfgang (Eds). The end of diversity? Prospects for German and Japanese capitalism. Ithaca e Londres: Cornell University Press, 2003, p. 147-182. COATES, David. Models of capitalism: Growth and stagnation in the modern era. Oxford: Polity Press, 304p., 2000, ISBN 0-7456-2058-2. 
ESTEVEZ-ABE, Margarita; IVERSEN, Torben e SOSKICE, David. "Social protection and the formation of skills: A reinterpretation of the Welfare State". In: HALL, Peter e SOSKICE, David (Eds). Varieties of capitalism - the institutional foundations of comparative advantage. Oxford: Oxford University Press, p. 145-183, 2001.

GOLDEN, Miriam; WALLERSTEIN, Michael e LANGE, Peter. "Postwar tradeunion organization and industrial relations in twelve countries". In: KITSCHELT, Herbert; LANGE, Peter; MARKS, Gary e STEPHENS, John (Eds). Continuity and change in contemporary capitalism. Cambridge: Cambridge University Press, p. 194-230, 1999.

GUIMARÃES, Alexandre Queiroz. Modelos de capitalismo e política comparada: Instituiçoes, performance e as respostas alemã e japonesa aos desafios recentes. (Artigo apresentado no Encontro da Associação Brasileira dos Pesquisadores em História Econômica.) Conservatória/RJ, Setembro, 2005.

HALL, Peter. "The political economy of Europe in an era of interdependence". In: KITSCHELT, Herbert; LANGE, Peter; MARKS, Gary e STEPHENS, John (Eds). Continuity and change in contemporary capitalism. Cambridge: Cambridge University Press, p. 135-163, 1999.

HALL, Peter e SOSKICE, David. "An introduction to varieties of capitalism". In: HALL, Peter e SOSKICE, David (Eds). Varieties of capitalism - the institutional foundations of comparative advantage. Oxford: Oxford University Press, p. 1-68, 2001.

JACKSON, Gregory. "Corporate governance in Germany and Japan: Liberalization pressures and responses during the 1990s". In: YAMAMURA, Kozo e STREECK, Wolfgang (Eds). The end of diversity? Prospects for German and Japanese capitalism. Ithaca e Londres: Cornell University Press, p. 261305, 2003.

JÜRGENS, Ulrick. "Transformation and interaction: Japanese, U.S., and German production models in the 1990s". In: YAMAMURA, Kozo e STREECK, Wolfgang (Eds). The end of diversity? Prospects for German and Japanese capitalism. Ithaca e Londres: Cornell University Press, p. 212-239, 2003.

PORTER, Michael. The competitive advantage of nations. Nova York: Free Press, 1990.

SCHMIDT, Vivien. The futures of european capitalism. Oxford: Oxford University Press. 357p, 2002, ISBN 0-19-925368-4.

SOSKICE, David. "Divergent production regimes: Coordinated and uncoordinated market economies in the 1980s and 1990s". In: KITSCHELT, Herbert; LANGE, Peter; MARKS, Gary e STEPHENS, John (Eds). Continuity and change in contemporary capitalism. Cambridge: Cambridge University Press, p. 101-134, 1999. 
STREECK, Wolfgang. "German capitalism: does it exist? Can it survive?" In: CROUNCH, Colin e STREECK, Wolfgang (Eds). Political economy of modern capitalism. London: Sage Publications, p. 33-54, 1997.

THELEN, Kathleen e KUME, Ikuo. "The future of nationally embebbed capitalism: Industrial relations in Germany and Japan". In: YAMAMURA, Kozo e STREECK, Wolfgang (Eds). The end of diversity? Prospects for German and Japanese capitalism. Ithaca e Londres: Cornell University Press, p. 183211, 2003.

VOGEL, Steven. "The re-organization of organized capitalism: How the German and Japanese models are shaping their own transformations". In: YAMAMURA, Kozo e STREECK, Wolfgang (Eds). The end of diversity? Prospects for German and Japanese capitalism. Ithaca e Londres: Cornell University Press, p. 306-333, 2003.

YAMAMURA, Kozo. "Germany and Japan in a new phase of capitalism: Confronting the past and the future." In: YAMAMURA, Kozo e STREECK, Wolfgang (Eds). The end of diversity? Prospects for German and Japanese capitalism. Ithaca e Londres: Cornell University Press, p. 115-146, 2003.

\section{Artigos consultados na Internet}

"One year of Agenda 2010 - reforms for Germany." Segunda-feira, 15 de março de 2004. Disponível em http://www.germanyembassy.org.uk. Acesso em 22/03/2005.

"Shouldering responsibility for our country: Building a stronger Germany - statement of Chancellor Gerhard Schröder to the Bundestag on the progress of the reform package Agenda 2010". Quinta-feira, 17 de março de 2005. Disponível em http://www.germanyembassy.org.uk.

Acesso em 22/03/2005.

"Workers cut back." Financial Times, Segunda-feira, 01 de novembro de 2004. Disponível em http://www.ft.com. Acesso em 03/11/2005. 


\section{D)}

\section{O CAPITALISMO COORDENADO ALEMÃO: DO BOOM DO PÓS- GUERRA À AGENDA 2010}

\section{ALEXANDRE QUEIROZ GUIMARÃES}

No pós-guerra constituiu-se na Alemanha um modelo de capitalismo coordenado, em que os sindicatos e as associações empresariais assumiram papel central. Constituíram-se várias formas de regulação via networks, presentes nas relações internas às firmas, nas formas de colaboração entre as empresas e na interação mais próxima entre bancos e empresas. Os bons resultados em termos de competitividade foram combinados com excelentes indicadores sociais. Entretanto, as transformações recentes, relacionadas à maior internacionalização produtiva e financeira, têm colocado em xeque o capitalismo socialmente coordenado. Em face aos desafios econômicos, a Alemanha vem reagindo, procurando reformas que tornem o modelo mais flexível. Mas aspectos centrais do modelo têm se conservado, com destaque para as relações de trabalho e os mecanismos de cidadania social.

Palavras-chave: Modelos de Capitalismo; Instituições; Alemanha; Capitalismo Coordenado; Economia Política.

\section{THE GERMAN COORDINATED CAPITALISM: FROM THE POST WAR BOOM TO AGENDA 2010}

The reconstruction of German political economy after the Second World War was marked by the consolidation of many forms of regulation via networks. Those networks, present in many areas of the economy, stimulated the cooperation among the actors, having critical implications for the performance of the model. The outstanding results in terms of competitivity combined with outstanding social indicators. In recent years, international transformations, including financial liberalisation 
and internationalisation of production, have placed the social coordinated capitalism in check. In face of the economic challenges, Germany has been adopting a range of reforms in the attempt to make the model more flexible. Nevertheless, central aspects of the coordinated capitalism have been preserved, including the system of industrial relations and the mechanisms of social citizenship.

Keywords: Models of Capitalism; Institutions; Coordinated Capitalism; Germany; Political Economy. 